\title{
Changes in Women's Choice of Dress Across the Ovulatory Cycle: Naturalistic and Laboratory Task-Based Evidence
}

\author{
Kristina M. Durante \\ Norman P. Li \\ University of Texas, Austin \\ Martie G. Haselton \\ University of California, Los Angeles
}

The authors tested the prediction that women prefer clothing that is more revealing and sexy when fertility is highest within the ovulatory cycle. Eighty-eight women reported to the lab twice: once on a low-fertility day of the cycle and once on a high-fertility day (confirmed using hormone tests). In each session, participants posed for full-body photographs in the clothing they wore to the lab, and they drew illustrations to indicate an outfit they would wear to a social event that evening. Although each data source supported the prediction, the authors found the most dramatic changes in clothing choice in the illustrations. Ovulatory shifts in clothing choice were moderated by sociosexuality, attractiveness, relationship status, and relationship satisfaction. Sexually unrestricted women, for example, showed greater shifts in preference for revealing clothing worn to the laboratory near ovulation. The authors suggest that clothing preference shifts could reflect an increase in female-female competition near ovulation.

Keywords: menstrual cycle; ovulation; clothing; female sexuality; sociosexuality

$\mathrm{H}$ ow we look affects who hires us and how quickly we get promoted, who we attract as mates and friends, and how we are evaluated through the routine social judgments people make of us in our daily lives (Langlois et al., 2000). The psychological literature is filled with insights about the features that contribute to attractiveness (e.g., Dion, 2002; Etcoff, 1999), and we know some things about changes in attractiveness over time-in particular, that it tends to decline. However, we know far less about intraindividual differences in attractiveness and their underlying motivation across shorter time spans. In this study, we investigate a key variable-the ovulatory cycle-that may contribute to day-by-day changes in women's motivations to appear attractive. We examine its effect on one of the factors over which women can exercise the most control: clothing choice.

\section{Ovulation and Women's Social Motivation}

Scientists have long believed that human ovulation is completely concealed, possibly even from women themselves (e.g., Burt, 1992). Chimpanzees, for example, show obvious indicators of the approach of ovulation through genital swelling; however, there is no clear parallel cue of cycling fertility in humans. Unlike many mammals, humans engage in sexual activity throughout the cycle (Alexander \& Noonan, 1979). Concealed ovulation and women's sexual receptivity outside of the fertile window were thought to have evolved to extend male investment and sexual interest throughout the entire cycle (Benshoof \& Thornhill, 1979; Brumbaugh \& Fraley, 2006; Thornhill, 2007), thereby promoting

Authors' Note: We are grateful to Inverness Medical Innovations for their generous donation of the Clearblue ${ }^{\circledR}$ Easy Ovulation Test Kits. We thank Sarah Hill, James Roney, Dario Maestripieri, Kelly Lang, Ruth Li, Elizabeth Pillsworth, Meg Cason, Greg Hixon, and Yla Tausczik for their helpful comments and contributions to this manuscript and project. Correspondence should be addressed to Kristina M. Durante, Department of Psychology, University of Texas, Austin, 1 University Station-A8000, Austin, TX 78712; email: kdurante@mail.utexas.edu.

PSPB, Vol. XX No. X, Month XXXX $\mathrm{xx}-\mathrm{xx}$

DOI: $10.1177 / 0146167208323103$

(C) 2008 by the Society for Personality and Social Psychology, Inc. 
socially monogamous bonds between men and women (Alexander \& Noonan, 1979). However, by making it more difficult for men to keep track of their mates' fertile window, concealment of ovulation may have also increased women's ability to mate and, thus, have offspring, with men other than the current partner (Haselton \& Gangestad, 2006; Thornhill, 2007).

Many of the greatest reproductive fitness benefits women can gain in their lifetimes are limited to the brief fertile window of the cycle when the probability of conception is highest. Accordingly, recent evolutionary models have proposed that women's mating psychology is sensitive to fertility status, and the approach of ovulation should shift women's social motives and behaviors in adaptive ways (e.g., Bullivant et al., 2004; Fessler, 2003; Gangestad, Garver-Apgar, Simpson, \& Cousins, 2007; Haselton \& Gangestad, 2006; Penton-Voak et al., 1999). Indeed, some evidence suggests that normally cycling women experience greater sexual desire and more frequent sexual fantasies during the fertile window of the cycle (Bullivant et al., 2004). Additional evidence indicates that this desire may be directed toward nonprimary partners (Gangestad, Thornhill, \& Garver, 2002), particularly if a woman's primary partner lacks specific indicators of genetic fitness, for example, symmetry (Gangestad, Thornhill, \& Garver-Apgar, 2005b), sexual attractiveness (Haselton \& Gangestad, 2006; Pillsworth \& Haselton, 2006), and major histocompatibility complex gene compatibility (Garver-Apgar, Gangestad, Thornhill, Miller, \& Olp, 2006). In line with such evidence, there is a rapidly growing body of work documenting corresponding shifts across the cycle in women's mate preferences (see Gangestad, Thornhill, \& GarverApgar, 2005a, for a review).

Other changes associated with ovulation include an increase in women's self-perceived attractiveness and feeling of sexiness (Haselton \& Gangestad, 2006), greater motivations to attend social gatherings (Haselton \& Gangestad, 2006), and greater distances traveled by foot and fewer calories consumed (both of which could reflect increases in mating motivation; Fessler, 2003). Further, fMRI research has found that women experience more activation of reward-related brain areas in the midfollicular phase of the menstrual cycle (Dreher et al., 2007). This implies that, near ovulation, women experience an increase in desire for immediate rewards, which may facilitate an escalation of mate-seeking behavior.

Recently, Fisher (2004) proposed an intriguing hypothesis about another shift in women's social motivations-specifically, that women become more intrasexually competitive near ovulation. As a test of this hypothesis, she asked women to rate other women's facial attractiveness; she found, as predicted, that women's ratings were lower at midcycle, signifying that women were derogating the competition when the reproductive stakes are highest. Fisher interpreted these results as evidence that women are especially inclined to compete intrasexually for access to "quality" mates when fertility is highest. Another study of female competitiveness found that women closest to the expected day of ovulation were less likely to share a monetary award and more likely to reject a low offer to share in a monetary stake with another woman (Lucas, Koff, \& Skeath, 2007). The authors proposed that near ovulation, women may be prone to compete for material resources. Taken together, both studies suggest that female intrasexual competitiveness may be especially strong during the most fertile part of the cycle.

\section{Cues of Ovulation}

As the foregoing review indicates, it is clear that women are, at some level, sensitive to cyclic shifts in their own fertility. The literature on ovulatory cues that are observable by others is much smaller, but emerging evidence points to a few possible indicators of ovulation. First, it is possible that people can detect ovulatory shifts in women's social behaviors directed toward others. For example, in several studies, women report that their primary partners are more jealous and possessive near ovulation as compared with other cycle points (Gangestad et al., 2002; Haselton \& Gangestad, 2006; also see Pillsworth \& Haselton, 2006). This could indicate that male partners detect variation in their partners' extrapair flirtation, which increases prior to ovulation (e.g., Gangestad et al., 2002; Haselton \& Gangestad, 2006). Second, it is possible that men have evolved to detect by-products of cycling hormones, including changes in body scent. Consistent with this proposal, several studies have shown that men rate the scent of T-shirts worn by women on fertile days of the cycle as more attractive than those worn on nonfertile days (Singh \& Bronstad, 2001; Thornhill et al., 2003). Miller, Tybur, and Jordan (2007) found that lap dancers earned more tips near ovulation as compared with other cycle phases; they speculated that this effect could be mediated by scent, among other ovulatory cues. Third, women may be altering their appearance across the cycle so that they appear more physically attractive when fertility is highest. For example, a recent study documented a shift in women's self-grooming and clothing choice (Haselton, Mortezaie, Pillsworth, Bleske, $\&$ Frederick, 2007)—probably the most easily observed ovulatory cue documented to date, thus opening up an intriguing avenue for further investigation.

In the clothing study, researchers photographed 30 women twice, once on a follicular phase day (high fertility) and once on a luteal phase day (low fertility), with 
luteinizing hormone tests verifying ovulation (Haselton et al., 2007). A separate set of male and female judges, blind to the fertility status of the photos, viewed the photo pairs with the faces concealed. They were asked, simply, "In which photo is she trying to look more attractive?" Judges chose the high-fertility photograph at above-chance levels (59.5\% of the time). Furthermore, the researchers found that a woman's high-fertility photograph was especially likely to be chosen if the woman participated in her high-fertility session on one of the days closest to ovulation (when fertility is especially high). Secondary coding of differences between the photographs indicated that the high-fertility photographs tended to feature women dressed "more fashionably" rather than more revealingly or sexy.

There are several competing explanations of why women's clothing preferences change across the cycle. One possibility is that women simply feel more attractive near ovulation (Haselton \& Gangestad, 2006) and they put more effort into their appearance as a result. Women might also dress nicely to attract extrapair mates, as some of the work on shifts in desires suggests (e.g., Gangestad et al., 2002). Another possibility is that women dress up more near ovulation as a result of an increase in intrasexual competitiveness (Fisher, 2004). In other words, women may be altering their physical attractiveness to enhance their ability to compete with other women, ultimately for access to higher quality mates. As Haselton and colleagues noted, however, none of these explanations could be directly tested in their study because the relevant individual difference variables were not assessed.

In summary, the long-held wisdom that ovulation is concealed is being overturned. Women appear to be sensitive to varying levels of hormones associated with ovulation, which lead to systematic changes in their social motivations, desires, and preferences. There is also growing evidence that other people-possibly including complete strangers-can detect cues of ovulation.

\section{The Current Study}

The primary aim of the current study was to further investigate changes in women's attractiveness-related behaviors, specifically clothing choices, across the cycle. In designing the study, we sought to address several limitations of the existing work. First, Haselton and colleagues (2007) photographed only 30 women, all of whom were involved in relationships. The current study examined a substantially larger sample of women, including both partnered and unpartnered women, as well as women who had experienced sexual intercourse and those who had not. Psychological mechanisms regulating female behavioral changes during the fertile window may be sensitive to sexual experience. It is not until a woman is sexually active that a problem like retaining choice over the biological father of offspring or promoting male investment in the relationship would become crucial. Second, in addition to taking photographs in the laboratory, we designed an outfit illustration method to assess women's likely clothing choices at social gatherings. We reasoned that whereas Haselton et al. did not find compelling evidence that women wore sexier clothing to campus near ovulation, this new method might provide us with greater power to detect such shifts. Ovulatory shifts in preference for sexy clothing may be more evident in clothing selected to wear to a social gathering where single, attractive peers are likely to be present and opposite-sex socializing will take place.

Third, we included several individual difference variables, including women's sociosexuality, self-perceived attractiveness, and satisfaction in their relationships (partnered women). These variables provide an important next step in understanding why women's clothing choices change. For example, if women dress up to attract extrapair mates, we should find a greater shift across the cycle for partnered than for unpartnered women. If, instead, shifts in clothing choice more generally reflect changes in women's intrasexual competitiveness, we might expect a greater change for women who are unpartnered (and thus actively seeking a mate), sexually unrestricted (and thus inclined to have short-term sexual liaisons), or both. Finally, various other menstrual cycle studies have used counting methods to estimate high-fertility days (e.g., Fisher, 2004; Roberts et al., 2004). To obtain greater accuracy, we utilized ovulation detection devices in order to pinpoint actual ovulation and, thus, to verify fertility.

\section{METHOD}

\section{Participants}

Participants were 88 female undergraduates at the University of Texas, Austin. All women were 17 to 30 years of age and normally ovulating (not using the pill or other hormonal contraceptive). Participants were compensated with research credit for a psychology course or with $\$ 30$. All 88 participants completed highfertility testing no more than 2 days prior to their luteinizing hormone $(\mathrm{LH}$; a pituitary hormone that peaks 24-36 hours prior to ovulation) surge and no later than 4 days following their LH surge and were considered to be fertile at the time of high-fertility testing (after Pillsworth \& Haselton, 2006). Mean age for these participants was $19.10(S D=1.77)$. One hundred 
sixty-five participants were originally recruited for this study. However, 30 participants did not complete both sessions (e.g., because of self-cited scheduling difficulties), and 47 did not show evidence of an LH surge during high-fertility testing. Our retention rate is similar to that reported in earlier studies using similar methods (Gangestad et al., 2002; Pillsworth \& Haselton, 2006).

\section{Procedure}

The key predictor variable in this research was fertility within the cycle. Therefore, following Pillsworth and Haselton (2006; also see Gangestad et al., 2002), we prescreened women over the telephone, and only women who reported none of the following were included in the study: current or recent use of hormonal contraceptives (i.e., use of hormonal contraceptives within the last 3 months), irregular cycle length (i.e., cycles running less than 25 days or more than 35 days long), recent birth of a child and/or currently breastfeeding a child, experience of dramatic changes in weight, use of antidepressants, or regular cigarette smoking.

On the basis of the information women provided about their cycles during the telephone prescreening interviews, each participant was scheduled to come into the lab for two experimental sessions-one on an expected high-fertility day and one on an expected lowfertility day. Women also reported to the lab to complete LH tests (unmarked over-the-counter urine applicator tests-Clearblue ${ }^{\circledR}$ Easy Ovulation Test Kit). The first urine test was scheduled 2 days before the expected day of ovulation. If an LH surge was not detected, women came back each day until an LH surge was detected or six tests had been completed, whichever came first. If any of the 6 days required to detect ovulation fell on a weekend, the participant was given testing sticks and directions to take the test at home and return it to the lab on Monday. On average, high-fertility testing sessions took place 0.227 days after the LH surge $(S D=1.72 ; 0.773$ days before day of ovulation, $S D=$ 1.72). Low-fertility sessions were scheduled 6 days or more after the LH surge or at least 3 days before onset of their menstrual periods. Twelve participants did not report the start date of their menstrual periods after completing the testing process. For these participants, days from menstrual onset at low-fertility testing was estimated from cycle information provided during their initial sessions. On average, low-fertility testing sessions took place 5.65 days prior to menses $(S D=2.88)$. Forty-nine participants completed high-fertility testing first, and 39 completed low-fertility testing first.

During each session, a full-body digital photograph of the participant was taken. Participants were instructed to stand with their hands at their sides. Participants were then taken to a private testing room to complete questionnaires and the outfit illustration task. Lighting conditions and location of testing remained constant across sessions and participants.

At each testing session, participants first completed several biographical measures. We administered the biographical survey at each session to examine whether women's responses might differ at high and low fertility. Significant differences between sessions did not exceed the Type I error rate, and there were no differences on the key measures listed below; thus, we collapsed across sessions to obtain a more reliable measure of each variable. The key measures are as follows:

Romantic relationship survey. Participants answered questions regarding their sexual histories, current romantic relationships, and relationship histories. Questions central to our predictions were whether or not the participants had experienced sexual intercourse and if they were involved in a romantic relationship, as well as ratings of relationship satisfaction-specifically, "sexual satisfaction with current relationship," "emotional satisfaction with current relationship," and "overall satisfaction with current relationship." Participants responded on 7-point rating scales (with the anchors $1=$ extremely dissatisfied and $7=$ extremely satisfied). Also, participants provided information regarding relationship length and commitment, whether or not sexual intercourse was experienced with the partner or anyone other than the partner, number of lifetime sexual partners, and how long the participant "usually dates someone before having sexual intercourse." For final analysis, ratings of sexual, emotional, and overall satisfaction with partner at high and low fertility were collapsed to form a composite satisfaction rating (high fertility $\alpha=.878$, low fertility $\alpha=.912$, and composite $\alpha=.902$ ).

Sociosexual Orientation Inventory. The SOI (Simpson \& Gangestad, 1991) measures an individual's willingness to have sexual intercourse without commitment (composite $\alpha=.970$ ). Item 4 asks, "How often do you fantasize about having sex with someone other than your current dating partner?" Because this item pertains only to participants currently involved in a romantic relationship, it was dropped so that SOI scores could be obtained for all women in the sample (after Haselton, 2003).

Desirability Scale. This instrument is designed to assess participant self-perceived attractiveness (after Haselton, 2003). The questions pertain to self-perceived desirability compared to same-sex peers. All items were rated on a 9-point scale. Five items were used to form an average composite attractiveness score: (1) "Compared with most women, how attractive is your body to men?" 


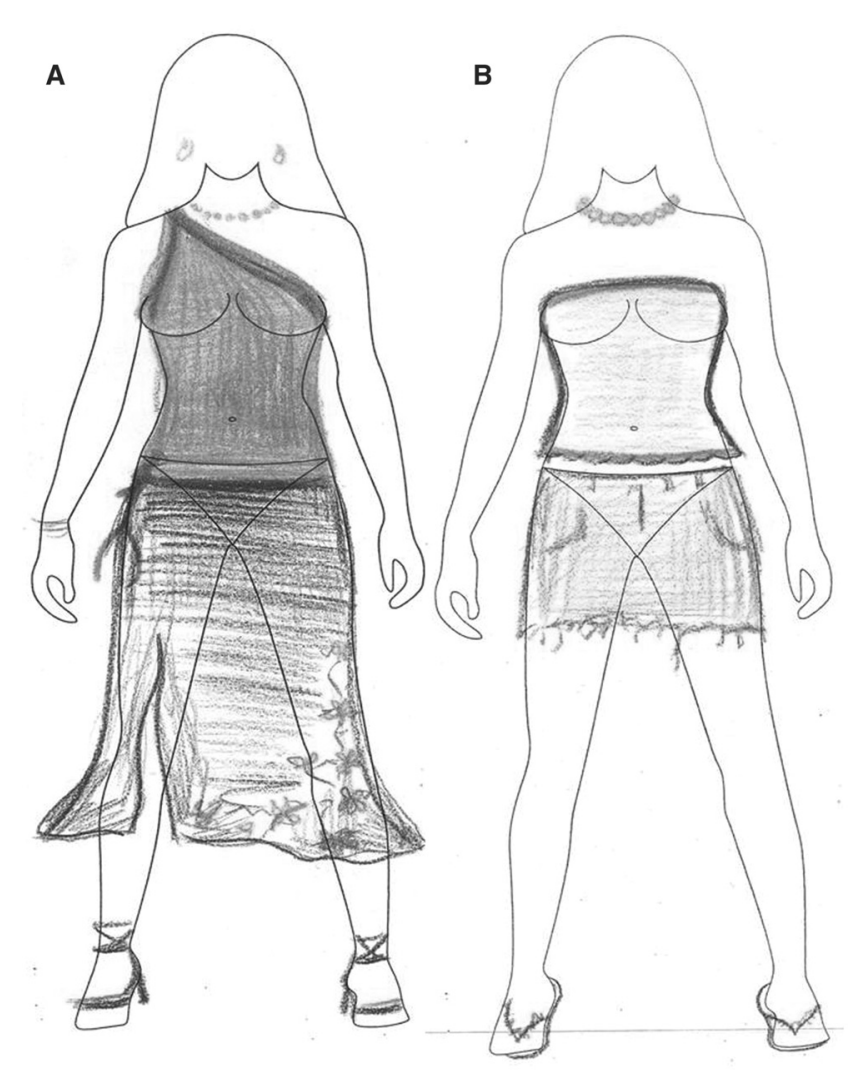

Figure 1 Example of an outfit illustration drawn by the same participant at low fertility (A) and high fertility (B).

(anchors: 1 = not at all attractive, $9=$ extremely attractive); (2) "Compared with most women, how attractive is your face to men?" ( $1=$ not at all attractive, $9=$ extremely attractive); (3) "Compared with most women, how sexy would men say you are?" $(1=$ not at all sexy, $9=$ extremely sexy); (4) "How desirable do you think men find you as a short-term mate or casual sex partner, compared to most women?" $(1=$ not at all desirable, $9=$ extremely desirable); and (5) "How desirable do you think men find you as a long-term mate or marriage partner, compared to most women?" $(1=$ not at all desirable, $9=$ extremely desirable). Items were averaged across high- and lowfertility testing sessions to form a composite self-perceived attractiveness score (high fertility $\alpha=.790$, low fertility $\alpha=.824$, and composite $\alpha=.913$ ).

Finally, during both high- and low-fertility sessions, participants were given the following instructions for the outfit illustration task:

Imagine that you are attending a social gathering at a friend's apartment tonight. From what this friend tells you, it is a large party where there will be a lot of single attractive people. The party starts at around 10:30 p.m.

Begin to decide on what you are going to wear to this party. Using the colored pencils provided, indicate on the paper doll what you will be wearing to this party by drawing an outfit, showing where the neckline will start on your shirt to where the shirt will end. Also indicate where your pants, shorts, skirt, etc. will begin and end.

Participants were then given a sheet of paper containing an outline of a woman's figure, upon which they sketched an outfit using colored pencils (see Figure 1).

To calculate the amount of skin exposed in each illustration, we used the following procedure: A blank figure outline was divided into 17 body regions, excluding extremities. This outline was photocopied onto a sheet of transparency film. A sheet of 1-millimeter graph paper was also copied onto the transparency film. Thus, the transparency film contained a figure outline that was divided into 17 regions and subdivided into 1-millimeter squares. Four research assistants, blind to the fertility status of the participant at the time the outfit was sketched, separately calculated the total amount of skin revealed in each region on each illustration. For each calculation, the transparency film was placed directly on top of the outfit illustration, and the coder counted the number of squares on the figure that contained exposed skin for each of the body regions. Coders counted in fractions $(.25, .50$, and .75$)$ when only a portion of a square contained exposed skin. After the four coders finished their separate calculations, they jointly resolved counting discrepancies in each body region for each illustration and submitted final counts. Thus, for each illustration, the total number of square millimeters of exposed skin across all 17 body regions represented the amount of total skin revealed on the outfit illustration.

The figure illustrations and digital photographs were rated by 22 male and 47 female undergraduates, blind to the purpose of the research. Images were randomized with respect to fertility status, and the high- and lowfertility photographs of a given participant were not presented consecutively. Images were presented one at a time. For the digital photographs, an opaque square covered the faces of the participants during presentation in order to eliminate any effects of facial appearance (e.g., differential facial expression across sessions). Raters were asked to rate the illustrations and photographs across the two dimensions of how "revealing" and how "sexy" the outfit appeared. Ratings were obtained using a 9-point scale $(1=$ not at all revealing/sexy, $9=$ extremely revealing/sexy). Agreement among judges was as follows: For the outfit illustration, revealing $\alpha=.978$ and sexy $\alpha=.876$. For the digital photographs, revealing $\alpha=.972$ and sexy $\alpha=.942$. 
TABLE 1: Summary of Results: Predictors of Increases in Skin Revealed in $\mathrm{mm}^{2}$, Revealingness, Sexiness, and Composite Photo Ratings at High Fertility Compared to Low Fertility

\begin{tabular}{|c|c|c|c|c|c|}
\hline & $\begin{array}{l}\text { Relationship } \\
\text { Status }\end{array}$ & $\begin{array}{c}\text { Sexual } \\
\text { Experience }\end{array}$ & $\begin{array}{c}\text { Sociosexual } \\
\text { Orientation } \\
\text { Inventory (SOI) }\end{array}$ & Attractiveness & $\begin{array}{l}\text { Relationship } \\
\text { Satisfaction }\end{array}$ \\
\hline Total skin $\left(\mathrm{mm}^{2}\right)$ & Single $>$ mated $*$ & $\begin{array}{l}\text { Had sex }>\text { no } \\
\text { experience* }\end{array}$ & ns & ns & $\begin{array}{l}\text { High }>\text { low } \\
\text { satisfaction* }\end{array}$ \\
\hline Revealing rating (figure) & Single $>$ mated $\dagger$ & $\begin{array}{l}\text { Had sex }>\text { no } \\
\text { experience } \dagger\end{array}$ & $n s$ & ns & $\begin{array}{l}\text { High }>\text { low } \\
\text { satisfaction* }\end{array}$ \\
\hline Sexy rating (figure) & ns & $n s$ & $n s$ & ns & ns \\
\hline Composite rating (photo) & Single $>$ mated $*$ & $\begin{array}{l}\text { Had sex }>\text { no } \\
\quad \text { experience } * *\end{array}$ & $\begin{array}{l}\text { Higher > } \\
\text { lower SOI** }\end{array}$ & $\begin{array}{l}\text { Lower }>\text { higher } \\
\text { attractiveness* }\end{array}$ & ns \\
\hline
\end{tabular}

$\dagger p<.10 .{ }^{*} p<.05 .{ }^{* *} p<.01$.

\section{RESULTS}

\section{Calculation of Composite Scores}

The sexy and revealing ratings for the clothing illustrations had low reliability when the two ratings were collapsed (high-fertility $\alpha=.257$; low-fertility $\alpha=.547$ ); therefore, these ratings remained separate for all analyses. Sexy and revealing ratings for the digital photographs had reasonable reliability and were collapsed to form a composite rating score (revealing/sexy ratings high-fertility $\alpha=.715$; revealing/sexy ratings low-fertility $\alpha=.666$ ).

\section{Statistical Analyses}

Analyses were run on each of the four dependent variables-total skin revealed in the clothing illustration, revealing rating of the clothing illustration, sexy rating of the clothing illustration, and composite rating of the digital photographs. Differences in the dependent measures across high- and low-fertility sessions were examined using repeated measures analysis (general linear models, SPSS 15.0). Session (high vs. low fertility) was a repeated factor in all analyses. The base model for primary analyses included three between-subjects factors. The first was proximity to ovulation within fertile session (measured as women who completed high-fertility testing on the day of LH surge or estimated ovulation day vs. women tested outside of the 2-day peak fertility window). Of the 88 participants, 33 completed high-fertility testing on the day of their LH surges or the following day. A surge in LH indicates that ovulation will typically occur within 24 to 36 hours. Because a mature ovum survives less than 24 hours, and sperm survive 72 hours or less, the greatest chance for conception occurs within 2 days of the LH surge (Eichner \& Timpe, 2004). Therefore, these 33 participants were presumed to be at highest risk for conception. The second between-subjects factor was sexual experience (had sex vs. had not had sex), and the third was relationship status (in a relationship vs. not in a relationship).
Analyses were run to examine the effects of order of session (high- vs. low-fertility session first) and days to menstrual onset (number of days until onset of menstruation following low-fertility testing) on the dependent measures. Neither order of session nor days to menstrual onset interacted with the independent variables of interest (e.g., high- vs. low-fertility session) in any of the analyses. Therefore, both order of session and days to menstrual onset were dropped from final analyses.

Finally, three sets of secondary exploratory analyses examined the effects of possible moderator variables of interest. Attractiveness score, SOI score, and relationship satisfaction score were added to the model as continuous, between-subjects independent variables. All continuous variables were $\log$ transformed to reduce skew in the data.

\section{Fertility and Clothing Choice}

There was an interaction between session and proximity to ovulation on total skin revealed on the outfit illustration, $F(1,80)=4.164, p=.045, d=.45$. Women closest to ovulation in their high-fertility session showed a greater increase in the amount of skin revealed at high fertility $\left(M=320.33 \mathrm{~mm}^{2}, S D=136.95\right)$ compared to low fertility $\left(M=260.91 \mathrm{~mm}^{2}, S D=154.36\right), F(1,84)=$ $3.22, p=.076, d=.39$. In contrast, women who completed high-fertility testing on other days showed little difference in total skin revealed from high-fertility $(M=$ $\left.256.41 \mathrm{~mm}^{2}, S D=125.11\right)$ to low-fertility testing $(M=$ $\left.270.63 \mathrm{~mm}^{2}, S D=140.98\right), F(1,84)=1.02, p=.316$, $d=.22$, but neither simple effect was significant.

The revealingness rating of the clothing illustration differed significantly between high- and low-fertility, $F(1,80)=4.702, p=.033, d=.49$, and this was strongly moderated by proximity to ovulation, $F(1,80)=7.240$, $p=.009, d=.60$. Women sketched outfits that were rated higher in revealingness at high fertility $(M=5.18$, $S D=1.49)$ compared to low fertility $(M=4.79, S D=$ $1.76), d=.24$. This difference was stronger for women 
who were closest to ovulation during their high-fertility session (high-fertility $M=5.63, S D=1.49$; low-fertility $M=4.76, S D=1.76), F(1,84)=6.48, p=.013, d=.56$.

For sexiness ratings of the clothing illustrations, a main effect of session, $F(1,80)=5.846, p=.018, d=.54$, indicated that illustrations were also rated as sexier at high fertility $(M=5.44, S D=1.17)$ than at low fertility $(M=5.17, S D=1.22), d=.23$.

In contrast to these effects for the illustrations, there was no difference between high- and low-fertility sessions, nor an interaction of session and proximity to ovulation, for the composite rating of the clothing worn to the lab on testing day.

\section{Sexual Experience and Clothing Choice}

For the outfit illustrations, there was a three-way interaction of sexual experience, proximity to ovulation, and session, $F(1,80)=5.488, p=.022, d=.52$, indicating that the effect of more skin being revealed during high fertility for women closest to ovulation in their high-fertility session was true only for sexually experienced women (high-fertility $M=387.28, S D=$ 140.92; low-fertility $M=259.487, S D=158.82), F(1$, $83)=5.62, p=.020, d=.52$. In contrast, sexually inexperienced women closest to ovulation showed no change in the amount of skin revealed across sessions (high-fertility $M=253.38, S D=132.48$; low-fertility $M=262.35, S D=149.31), F(1,83)=.00 . p=.953, d=$ .00. Sexual experience did not moderate the effect of fertility on the revealing or the sexy ratings of the outfit illustration.

For the composite ratings of clothing worn to the lab, there was an interaction between session and sexual experience, $F(1,64)=11.145, p=.001, d=.83$. Women who had not experienced sexual intercourse received higher ratings at low fertility $(M=2.94, S D=1.12)$ than at high fertility $(M=2.37, S D=1.12), F(1,68)=$ $6.61, p=.012, d=.62$. The reverse was true for women with sexual experience (high-fertility $M=3.16, S D=$ 1.15; low-fertility $M=2.84, S D=1.15), F(1,68)=4.46$, $p=.038, d=.51$.

\section{Relationship Status and Clothing Choice}

For the outfit illustrations, there was a three-way interaction of relationship status, proximity to ovulation, and session, $F(1,80)=4.318, p=.040, d=.46$, indicating that women closest to ovulation in their highfertility session who were not in committed relationships $(n=15)$ revealed a markedly greater amount of skin on the illustration during high fertility than during low fertility (high-fertility $M=367.91, S D=132.48$; lowfertility $M=238.00, S D=149.31), F(1,83)=5.42, p=$
$.022, d=.51$. In contrast, women closest to ovulation in their high-fertility session who were currently involved in romantic relationships $(n=18)$ showed no change in skin revealed across sessions (high-fertility $M=272.75$, $S D=140.92$; low-fertility $M=283.83, S D=158.82$ ), $F(1,83)=0.03, p=.861, d=.04$. Relationship status did not moderate the effect of session on the revealing rating or the sexy rating of the outfit illustration.

For composite ratings of the digital photographs of clothing worn to the lab on the testing day, there was a significant interaction between session and relationship status, $F(1,64)=4.551, p=.037, d=.53$, indicating that women who were in committed relationships showed more skin and wore sexier outfits at low fertility $(M=$ 3.04, $S D=1.13)$ than at high fertility $(M=2.64, S D=$ $1.12), F(1,68)=2.50, p=.119, d=.38$, whereas the results were somewhat in the opposite direction for single women (high-fertility $M=2.91, S D=1.14$; low-fertility $M=2.73, S D=1.15), F(1,68)=1.06, p=.306, d=.25$, but neither simple effect was significant.

\section{Attractiveness and Clothing Choice}

The self-perceived attractiveness variable moderated the effect of session on clothing choice for the photographs of clothing worn to the lab on testing day, $F(1$, $63)=4.779, p=.033, d=.55$. Women with lower selfperceived attractiveness wore outfits that were more revealing and sexy near ovulation compared to during low fertility. Self-perceived attractiveness score did not moderate the effect of session for the outfit illustration.

\section{SOI and Clothing Choice}

SOI score did not emerge as a significant predictor of the effect of fertility on clothing choice for the clothing illustration. For the digital photo composite ratings, there was a significant interaction between session and SOI score, $F(1,66)=13.031, p=.001, d=.89$. Compared to sexually restricted women, unrestricted women displayed more skin and wore outfits that were rated as sexier and more revealing at high fertility than at low fertility.

\section{Relationship Satisfaction and Clothing Choice}

Looking at women in relationships, the effect of session on total skin revealed on the outfit illustration was moderated by a woman's reported satisfaction with her romantic relationship partner, $F(1,35)=4.325, p=$ $.045, d=.70$, partial $r(38)=.341, p=.031$. An interaction also emerged between session and relationship satisfaction for the revealing ratings of the outfit illustration, $F(1,35)=4.787, p=.035, d=.74$, partial $r(38)=.324, p=.042$. Women reporting high levels of satisfaction with their romantic partners revealed more 
skin in their outfit illustrations and received higher revealing ratings at high fertility. There was no interaction between session and relationship satisfaction for the sexy ratings of the clothing illustration or for the digital photo composite rating.

\section{DISCUSSION}

Results support our main prediction that women prefer clothing that is more revealing and sexy near the onset of ovulation, particularly in mating-relevant contexts. When asked to illustrate what they would wear to a social event, women sketched outfits that were sexier and more revealing when they were nearest to ovulation. The illustrations also revealed more skin at high fertility compared to low fertility but only for women who completed testing on the 2 days of peak conception probability within the high-fertility window. Overall, ratings of digital photographs taken in the laboratory did not differ significantly between high- and low-fertility sessions.

We examined whether several individual difference variables would moderate the effect of session on clothing choices. Out of a total of 20 tests, the results of 8 were statistically significant. As predicted, women who were sexually experienced and at peak fertility revealed more skin on the outfit illustration at high versus low fertility, whereas sexually inexperienced women did not show this effect. SOI score moderated the predicted effect of session on the revealing and sexy ratings of the photographs-increases in these ratings from low to high fertility were greater for sexually unrestricted women than for sexually restricted women. Previous research documented that a woman's choice for revealing and sheer clothing was predictive of her motivation for sex (Grammer, Renninger, \& Fischer, 2004). A second study showed that women who were taking modest doses of testosterone, a hormone correlated with sexual motivation in women (van Anders, Hamilton, \& Watson, 2007), wore more attractive clothing than did women in the control condition (Dabbs et al., 2003). Our results extend these findings and suggest that women who are more open to casual sexual encounters desire outfits that are more revealing and wear clothing that is sexier specifically at high fertility.

Revealing clothing was preferred at high fertility by single women rather than by partnered women, suggesting that shifts in choice of clothing may reflect shifts in social motivations that are more relevant to single than to partnered women. Single women may have greater reason to compete on the mating market than women who are partnered; thus, it is possible that preference for revealing clothing near ovulation is a reflection of an increase in intrasexual competition.

For women in committed relationships, relationship satisfaction moderated the effect of session on clothing choice. When performing the outfit illustration task, the more satisfied women were with their primary partners, the greater they shifted their preference toward revealing clothing during high versus low fertility. From an intrasexual competition perspective, one possible interpretation is that if mated women are highly satisfied with their partners, they may be inclined to increase their attractiveness in order to remain competitive with members of the opposite sex for their mates' attention, especially at a time when mating decisions can result in potentially high consequences (at high fertility). That is, when a woman is most fertile, the costs of losing a desirable mate are highest, and thus, an increased motivation to appear more attractive than same-sex peers has the largest potential payoff. However, this interpretation is somewhat speculative, and another possibility is simply that this particular finding is spurious, given the large number of moderator analyses we conducted. Further work with more direct measures of female competition is required to verify the female competition hypothesis in this case.

For the clothes that women wore to the lab, selfperceived attractiveness moderated the effect of fertility on clothing choice. Women of lower self-perceived attractiveness experienced a stronger shift in preference for revealing and sexy clothing near ovulation. It is possible that an ovulatory increase in clothing sexiness may have the largest return for those of low attractiveness. Wearing short skirts and low-cut tops can be risky-revealing too much skin may attract unwanted attention from undesirable men or lead to reputational damage for appearing promiscuous. Given these costs, the marginal benefit of revealing more skin may be too small for women who are already able to compete (i.e., women high in attractiveness). Although this line of reasoning is also speculative, it is consistent with the notion that shifts in clothing preferences reflect female-female competition.

There are several possible explanations for menstrual cycle-related shifts in clothing preference. For instance, shifts in clothing preference may reflect hormone-mediated changes in motivation resulting from cycle shifts in sexual interest and sociability (e.g., Fessler, 2003; Gangestad et al., 2002). That is, women may generally feel greater sexual desire around the time of ovulation and, thus, may be motivated to dress more attractively. Another possibility is that, under certain conditions, women may pay more attention to their attire to attract extrapair mates. Along these lines, previous research has found stronger cycle shifts in sexually related female behavior for mated women (Havlicek, Roberts, \& Flegr, 2005; 
Pillsworth, Haselton, \& Buss, 2004; also see Little, Jones, Penton-Voak, Burt, \& Perrett, 2002). Researchers reasoned that shifts in desires and preferences across the cycle (e.g., increased desire for men other than one's primary partner) may be designed to secure genetic benefits for offspring through an extrapair copulation with a mate displaying indicators of good genes (Gangestad et al., 2005b; Haselton \& Gangestad, 2006; Pillsworth $\&$ Haselton, 2006). However, we found that single women were more likely than mated women to favor sexy and revealing clothing during the window of high fertility. Thus, the pattern of results from our sample of women is more consistent with a general intrasexual competitiveness explanation. That is, motivation to compete intrasexually and, thus, to be more attractive for potential mates may be high especially at the time when conception is most likely.

This is the first study to document ovulatory cycle shifts in clothing preferences using both a naturalistic task and a laboratory task designed to elicit clothing choices in a mating-relevant context. Overall, evidence for a cycle shift in choice of dress was stronger for the laboratory task (clothing illustrations). Designing an outfit to wear to a social event enabled participants to express motivations that are likely quite different from the motivations involved in selecting an outfit to wear to class. Parties and other social outings are contexts in which people seek to attract mates, and these may amplify same-sex competition. It is also likely that norms of daytime dress warrant less explicitly sexy clothing. As such, women may pay less attention to clothing worn to classes on a daily basis and, perhaps, vary the sexiness of their choices less than when dressing for a social event. Interestingly, we did find evidence that the most sexually unrestricted women in our sample preferred sexy and revealing clothing at high fertility across both contexts (worn to the lab and drawn for their imagined evening out), perhaps because their sexual motivations are generally higher than those of other women.

\section{Control for Confounds, Limitations, and Future Directions}

In this study, we compared days leading up to ovulation in the follicular phase and days following ovulation and preceding menstrual onset in the luteal phase. This research design raises the question of whether physiological events leading to ovulation or events preceding menstrual onset drove our effects. For example, it is possible that in the low-fertility session proximity to menstrual onset and its associated premenstrual symptoms led women to "dress down," as opposed to proximity to ovulation leading women to "dress up." However, we found no evidence that this was the case.
We found no interactions involving days to menstrual onset and high- versus low-fertility differences for any of the dependent variables, thus ruling out the possibility that women's experience of premenstrual symptoms impacted our results.

A potential limitation is that some of the findings had a small effect size, and many only reached conventional significance. Although our sample size was relatively large for an ovulatory cycle study, we investigated a host of variables, including three that were measured between women. Thus, statistical power for certain tests was modest. Replication of some of our key findings is needed in order to draw firm conclusions.

Also, clothing and fashion are modern phenomena in the context of deep evolutionary time. Although our work and other recent work (Haselton et al., 2007) suggest the operation of evolved mechanisms connected with cycling fertility, further research is needed to examine the precise evolved function, if any, of the motivations underlying cycle shifts in clothing choice. One possibility is to directly manipulate female intrasexual mate competition. For example, researchers could introduce an attractive-rival manipulation involving average versus highly attractive female confederates in the presence of single men. If attractive rivals induce a strong fertility effect in the presence of potential mates, we may have more reason to believe that intrasexual mate competition may underlie fertility shifts in clothing preferences.

Research elsewhere has identified a variety of tactics used in intrasexual mate competition (e.g., Buss, 1988). Additional research could investigate the use of these and other intrasexual competition tactics across the menstrual cycle, such as competitor derogation and willingness to incur debt to purchase expensive, fashionable clothing or otherwise conspicuously consume to improve one's attractiveness (e.g., Griskevicius et al., 2007).

\section{Conclusion}

In summary, the present study provides both laboratory and naturalistic evidence that women change their choice of dress across the ovulatory cycle. More generally, we have attempted to investigate intraindividual differences in motivations to appear attractive. In doing so, we have identified a key predictor variable-the ovulatory cycle-and have opened up the field for future investigations that may further explain such variation.

This research adds to the recent body of evidence showing that ovulation in humans is not completely concealed. Regardless of the underlying motivations involved, changes in women's clothing choices are notable, as they provide readily observable cues of ovulation that even complete strangers can observe. 


\section{REFERENCES}

Alexander, R. D., \& Noonan, K. (1979). Concealment of ovulation, parental care, and human social evolution. In N. A. Chagnon \& W. Irons (Eds.), Evolutionary biology and human behavior: An anthropological perspective (pp. 402-435). North Scituate, MA: Duxbury.

Benshoof, L., \& Thornhill, R. (1979). The evolution of monogamy and loss of estrus in humans. Journal of Social and Biological Structures, 2, 95-106.

Brumbaugh, C. C., \& Fraley, R. C. (2006). The evolution of attachment in romantic relationships. In M. Mikulincer \& G. Goodman (Eds.), The dynamics of romantic love: Attachment, caregiving, and sex. New York: Guilford.

Bullivant, S. B., Sellergren, S. A., Stern, K., Spencer, N. A., Jacob, S., Mennella, J. A., et al. (2004). Women's sexual experience during the menstrual cycle: Identification of the sexual phase by noninvasive measurement of luteinizing hormone. Journal of Sex Research, 41, 82-93.

Burt, A. (1992). Concealed ovulation and sexual signals in primates. Folia Primatologica, 58, 1-6.

Buss, D. M. (1988). The evolution of human intrasexual competition: Tactics of mate attraction. Journal of Personality and Social Psychology, 54, 616-628.

Dabbs, J. M., Cate, K., Brower, A., Emery, C., Leander, P., \& Zachery, M. (2003). Testosterone treatment, affect, and appearance: Slight effects in normal subjects. Social Behavior and Personality, 31, 387-394

Dion, K. (2002). Cultural perspectives on facial attractiveness. In G. Rhodes \& L. A. Zebrowitz (Eds.), Facial attractiveness: Evolutionary, cognitive, and social perspectives (pp. 239-259). Westport, CT: Ablex.

Dreher, J., Schmidt, P. J., Kohn, P., Furman, D., Rubinow, D., \& Berman, K. F. (2007). Menstrual cycle phase modulates rewardrelated neural function in women. Proceedings of the National Academy of Sciences, 104, 2465-2470.

Eichner, S. F., \& Timpe, E. M. (2004). Urinary-based ovulation and pregnancy: Point-of-case testing. Annals of Pharmacotherapy, 38, 325-331.

Etcoff, N. (1999). Survival of the prettiest. New York: Doubleday.

Fessler, D. M. T. (2003). No time to eat: An adaptationist account of periovulatory behavioral changes. Quarterly Review of Biology, $78,3-21$.

Fisher, M. L. (2004). Female intrasexual competition decreases female facial attractiveness. Proceedings of the Royal Society of London, Biology Letters, 271, 283-285.

Gangestad, S. W., Garver-Apgar, C. E., Simpson, J. A., \& Cousins, A. J. (2007). Changes in women's mate preferences across the ovulatory cycle. Journal of Personality and Social Psychology, 92, 151-163.

Gangestad, S. W., Thornhill, R., \& Garver, C. E. (2002). Changes in women's sexual interests and their partner's mate-retention tactics across the menstrual cycle: Evidence for shifting conflicts of interest. Proceedings of the Royal Society of London B, 269, 975-982.

Gangestad, S. W., Thornhill, R., \& Garver-Apgar, C. E. (2005a). Adaptations to ovulation. In D. M. Buss (Ed.), The handbook of evolutionary psychology (pp. 344-371). Hoboken, NJ: John Wiley.

Gangestad, S. W., Thornhill, R., \& Garver-Apgar, C. E. (2005b). Women's sexual interests across the ovulatory cycle depend on primary partner development instability. Proceedings of the Royal Society of London B, 272, 2023-2027.

Garver-Apgar, C. E., Gangestad, S. W., Thornhill, R., Miller, R. D., \& Olp, J. J. (2006). Major histocompatibility complex alleles, sexual responsivity, and unfaithfulness in romantic couples. Psychological Science, 17, 830-835.

Grammer, K., Renninger, L., \& Fischer, B. (2004). Disco clothing, female sexual motivation, and relationship status: Is she dressed to impress? Journal of Sex Research, 41, 66-74.
Griskevicius, V., Tybur, J. M., Sundie, J. M., Cialdini, R. B., Miller, G. F., \& Kenrick, D. T. (2007). Blatant benevolence and conspicuous consumption: When romantic motives elicit strategic costly signals. Journal of Personality and Social Psychology, 93, 85-102.

Haselton, M. G. (2003). The sexual overperception bias: Evidence of a systematic bias in men from a survey of naturally occurring events. Journal of Research in Personality, 37, 43-47.

Haselton, M. G., \& Gangestad, S. W. (2006). Conditional expression of women's desires and men's mate guarding across the ovulatory cycle. Hormones and Behavior, 49, 509-518.

Haselton, M. G., Mortezaie, M., Pillsworth, E. G., Bleske, A. E., \& Frederick, D. A. (2007). Ovulatory shifts in human female ornamentation: Near ovulation, women dress to impress. Hormones and Behavior, 51, 40-45.

Havlicek, J., Roberts, S. C., \& Flegr, J. (2005). Women's preference for dominant male odour: Effects of menstrual cycle and relationship status. Biology Letters, 1, 256-259.

Langlois, J. H., Kalakanis, L., Rubenstein, A. J., Larson, A., Hallam, M., \& Smoot, M. (2000). Maxims or myths of beauty? A meta-analytic and theoretical review. Psychological Bulletin, 126, 390-423.

Little, A. C., Jones, B. C., Penton-Voak, I. S., Burt, D. M., \& Perrett, D. I. (2002). Partnership status and the temporal context of relationships influence human female preferences for sexual dimorphism in male face shape. Proceedings of the Royal Society of London, B, 269, 1095-1100.

Lucas, M., Koff, E., \& Skeath, S. (2007). A pilot study of relationship between fertility and bargaining. Psychological Reports, 101, 302-310.

Miller, G. F., Tybur, J., \& Jordan, B. (2007). Ovulatory cycle effects on tip earnings by lap-dancers: Economic evidence for human estrus? Evolution and Human Behavior, 28, 375-381.

Penton-Voak, I. S., Perrett, D. I., Castles, D. L., Kobayashi, T., Burt, D. M., Murray, L. K., et al. (1999). Menstrual cycle alters face preference. Nature, 399, 741-742.

Pillsworth, E. G., \& Haselton, M. G. (2006). Male sexual attractiveness predicts differential ovulatory shifts in female extra-pair attraction and male mate retention. Evolution and Human Behavior, 27, 247-258.

Pillsworth, E. G., Haselton, M. G., \& Buss, D. M. (2004). Ovulatory shifts in female sexual desire. Journal of Sex Research, 41, 55-65.

Roberts, S. C., Havlicek, J., Flegr, J., Hruskova, M., Little, A. C., Jones, B. C., et al. (2004). Female facial attractiveness increases during the fertile phase of the menstrual cycle. Proceedings of the Royal Society of London B (Suppl.), 271, S270-S272.

Simpson, J. A., \& Gangestad, S. W. (1991). Individual differences in sociosexuality: Evidence for convergent and discriminant validity. Journal of Personality and Social Psychology, 60, 870-883.

Singh, D., \& Bronstad, P. M. (2001). Female body odor is a potential cue to ovulation. Proceedings of the Royal Society of London, Biology, 268, 797-801.

Thornhill, R. (2007). The evolution of women's estrus, extended sexuality, and concealed ovulation, and their implications for human sexuality research. In S. W. Gangestad \& J. A. Simpson (Eds.), The evolution of mind: Fundamental question and controversies (pp. 391-396). New York: Guilford.

Thornhill, R., Gangestad, S. W., Miller, R., Scheyd, G., McCollough, J. K., \& Franklin, M. (2003). Major histocompatibility complex genes, symmetry, and body scent attractiveness in men and women. Behavioral Ecology, 14, 668-678.

van Anders, S. M., Hamilton, L. D., \& Watson, N. V. (2007). Multiple partners are associated with higher testosterone in North American men and women. Hormones and Behavior, 51, 454-459.

Received September 4, 2007

Revision accepted April 7, 2008 